\title{
LER, DEBATER, REFLETIR E POSTAR: EM BUSCA DE NOVAS PERSPECTIVAS NA FORMAÇÃO DE PROFESSORES DE LÍNGUAS A PARTIR DE UMA DISCIPLINA SOBRE CRENÇAS NA PÓS-GRADUAÇÃO
}

\author{
READING, DEBATING, REFLECTING AND POSTING: IN SEARCH OF NEW \\ PERSPECTIVES IN LANGUAGE TEACHER TRAINING THROUGH A SUBJECT ABOUT \\ BELIEFS IN A POSTGRADUATE COURSE
}

Cristiane Manzan Perine

Fernanda Costa Ribas

UFU

RESUMO: Em um entremeio entre a cognição e a afetividade, as crenças correspondem a uma firme convicção, opinião ou ideia que o indivíduo tem em relação a algo (ALVAREZ, 2007), as quais são inter-relacionadas com o meio em que vivem e relacionadas à ação. Cada professor traz um repertório de crenças que revela diferentes atitudes, percepções, interpretações, escolhas e trajetórias percorridas na carreira docente. A tentativa de explorar essas crenças nos ajuda na compreensão de seus modos de pensar a prática docente e o ensino de línguas, uma vez que suas crenças determinam seus saberes e ações. Nesta apresentação, temos como objetivo apresentar e discutir as crenças de professores sobre diferentes aspectos envolvidos no ensino de línguas. Os dados foram coletados na disciplina "Crenças no ensino/aprendizagem de línguas: interfaces afetivas e contextuais", ofertada pelo Curso de Pós-Graduação em Estudos Linguísticos de uma universidade federal em Minas Gerais. As crenças dos professores foram identificadas a partir de tarefas e discussões nos fóruns semanais da disciplina na plataforma Moodle, a qual foi empregada de forma complementar às aulas presenciais.

PALAVRAS-CHAVE: crenças de professores; formação docente; pós-graduação; reflexão

ABSTRACT: In the boundary between cognition and affection, beliefs correspond to a steady conviction, opinion or idea the individual has in relation to something (ALVAREZ, 2007), which are inter-related to the environment they live and related to the action. Each teacher brings along a repertoire of beliefs that reveals different attitudes, perceptions, interpretations, choices and trajectories taken during the teacher career. The attempt to explore these beliefs help us in the comprehension of teachers' ways of thinking the teaching practice and the teaching of languages since beliefs determine their knowledge and actions. In this article, we have the goal to present and discuss teachers' beliefs about different aspects involved in the teaching of languages. The data were collected during the subject "Beliefs in language teaching/learning: affective and contextual interfaces". It is offered by the postgraduate course in Linguistics Studies of a federal university in Minas Gerais. The teachers' beliefs were identified from tasks and discussions on the weekly forums of the subject on Moodle platform, which was employed as a complement to the face-to-face classes. 


\section{Revista do SELL}

v. $4, n^{\circ} .1$

ISSN: $1983-3873$

KEYWORDS: teaches' beliefs; teacher training; post-graduate course; reflection

\section{Introdução}

Crenças no ensino e aprendizagem de línguas podem ser definidas como opiniões e ideias que alunos e professores têm a respeito dos processos de ensino e aprendizagem de línguas (BARCELOS, 2006). No Brasil, desde a década de 1990 os estudos sobre crenças em Linguística Aplicada (LA) têm trago grandes contribuições para o entendimento da atmosfera da sala de aula (seja ela virtual ou presencial), das relações entre professores e alunos, da abordagem de aprendizagem, metodologia de ensino e, notoriamente, das ações de professores e aluno frente à aprendizagem da língua.

A partir de um breve levantamento de estado da arte, Vieira-Abrahão (2010) ressalta os diversos contextos de estudos sobre crenças no Brasil na área de LA que têm sido desenvolvidos, dentre eles, centros de línguas, escolas de idiomas, escolas públicas, escolas privadas (ensino fundamental e médio), universidades privadas e públicas e, em número ainda reduzido, o contexto tecnológico de ensino e aprendizagem de línguas. Os estudos de crenças tendem a ser qualitativos e adotam métodos variados de coleta de dados: observação de aula, diários, questionários, entrevistas, autorrelatos, gravações em áudio e vídeo, sessões de visionamento e até mesmo desenhos (VIEIRA-ABRAHÃO, 2006). Neste estudo, adotamos como participantes de pesquisa pós-graduandas de uma universidade pública e propomos um novo instrumento de coleta de dados em pesquisas de crenças: os fóruns de discussão em uma plataforma virtual.

Considerando que as crenças exercem grande poder em influenciar as ações de professores, torna-se significativo investigar as crenças de professores em formação continuada e buscar meios de inserir o estudo sobre crenças nos estudos de pósgraduação. Assim, esses professores têm a oportunidade de conhecer e/ou aprofundar seu conhecimento teórico sobre crenças e seu impacto em sua prática docente e, através da discussão à luz de referencial teórico pertinente e da interação com outros colegas professores, sob a mediação de um professor formador, serem levados a refletir sobre suas próprias crenças. Dessa forma, buscamos como contexto de pesquisa deste estudo qualitativo a disciplina "Crenças no ensino/aprendizagem de línguas: interfaces afetivas e 


\section{Revista do SELL}

v. $4, n^{\circ} .1$

ISSN: $1983-3873$

contextuais", ofertada pelo programa de Pós-Graduação em Estudos Linguísticos de uma universidade federal no interior de Minas Gerais. Cursaram a disciplina sete alunas no curso de mestrado, as quais juntamente com a professora formada constituem as participantes deste estudo.

A disciplina teve como objetivo geral promover a análise e discussão sobre 0 papel das crenças e autocrenças no processo de ensino e aprendizagem de línguas e suas relações com fatores afetivos (motivação e ansiedade) e fatores provenientes dos contextos de ensino e aprendizagem, presenciais e virtuais. A metodologia da disciplina consistiu em aulas expositivo-dialogadas e seminários semanais, compondo uma carga horária de 60h, a qual foi complementada por atividades a serem realizadas semanalmente na plataforma Moodle (fóruns de discussão e tarefas).

Os fóruns recobriram propostas variadas: tópicos a serem escolhidos e discutidos por cada um dos participantes; perguntas envolvendo conceitos específicos trazidos pelos textos; proposta aberta de postagem de comentários, dúvidas e perguntas ao grupo e questões que permitiam que os alunos refletissem sobre suas crenças e experiências prévias e atuais de ensino e aprendizagem de línguas. Neste estudo, em fase inicial, focalizamos as interações entre alunas e professora formadora nos fóruns de discussão realizados no Moodle com o objetivo de analisar e discutir as crenças sobre o ensino e a aprendizagem de línguas expressas por meio dos fóruns de discussão. Podemos destacar o quanto esses fóruns funcionaram como um alargamento do tempo de sala de aula e forneceram espaço para debate e reflexão de crenças.

Entendemos que é importante que haja espaço e oportunidade tanto para alunos quanto para professores para desafio e questionamento de suas crenças (BARCELOS, 2007), pois, como afirma Barcelos (2006, p. 18), as crenças são "coconstruídas em nossas experiências", podendo ser significadas e ressignificadas. Concluímos que os fóruns de discussão podem ser grandes aliados nesse sentido.

Na primeira seção deste artigo, dedicada ao referencial teórico que embasou a condução deste estudo, conceituamos o termo crenças. Na segunda, expomos a metodologia de pesquisa empregada. Na terceira seção, trazemos a análise dos dados. Por fim, na quarta seção, as considerações finais mostram alguns apontamentos revelados por este estudo em fase inicial. 


\section{Revista do SELL}

v. $4, n^{\circ} .1$

ISSN: $1983-3873$

\section{Referencial teórico}

Alvarez (2007) define crenças como uma firme convicção, opinião ou ideia que o indivíduo tem em relação a algo. Crenças são (co)construídas, reconstruídas e apropriadas através da experiência adquirida e são internalizadas como parte do repertório de crenças de aprendizagem de segunda língua do aprendiz (GABILLON, 2005). Ao formular sua definição de crenças como firmes convicções que temos em relação a algo, Alvarez (2007) afirma que essas convicções repercutem nas ações de professores e na formulação de novas expectativas. A autora explicita ainda que as crenças são fortemente marcadas pelas experiências do indivíduo. Em seus dizeres:

Essa convicção está ligada a intuições que têm como base as experiências vivenciadas, o tipo de personalidade e a influência de terceiros, pois elas são construídas socialmente e repercutem nas suas intenções, ações, comportamento, atitude, motivações e expectativas (ALVAREZ, 2007, p. 200).

As crenças que alguém possui influenciam as percepções, atitudes e julgamentos dos indivíduos, o que, por sua vez, afeta o comportamento (PAJARES, 1992). Desse modo, diversos fatores enfatizam que existe uma implicada relação entre crenças e ações. Cada professor traz um repertório de crenças que revela diferentes atitudes, percepções, interpretações, escolhas e trajetórias percorridas na carreira docente. Nessa mesma linha de pensamento, fundamentada nas crenças como elemento que nos leva a agir, Pajares (1992) as descreve utilizando termos como "instrumentos" ou "ferramentas" que são utilizadas pelos alunos e professores ao aprender ou ensinar uma língua. Crenças interferem nas ações e tomadas de decisões. Conforme sua definição:

as crenças são instrumentos na definição das tarefas na seleção das ferramentas cognitivas com as quais pode-se interpretar, planejar, tomar decisões. Portanto, elas desempenham um papel crítico na definição de comportamentos e na organização de conhecimentos e informações (PAJARES, 1992, p. 325). 


\section{Revista do SELL}

v. $4, n^{\circ} .1$

ISSN: $1983-3873$

Pajares (1992, p. 307) discute que as crenças estão relacionadas não apenas ao ensino, mas também à natureza humana de forma geral, e pondera sobre o poder que nossas crenças têm de influenciar nossas decisões e ações. Para o autor, esta visão é baseada na suposição de que crenças são os melhores indicadores das decisões que as pessoas fazem no decorrer de suas vidas. Baseando-se, então, na complexa relação entre crenças e ações, Barcelos (2006) afirma que esta é uma relação direta, posto que "crenças e ações interagem e formatam umas às outras" (p. 43). Assim, as crenças são importantes instrumentos na definição de tarefas e seleção de ferramentas cognitivas com as quais um indivíduo se autointerpreta, planeja e toma decisões.

De acordo com Vieira-Abrahão (2005), os professores são altamente influenciados por suas crenças, que por sua vez, são reflexo de seus valores pessoais e de seus conhecimentos prévios. Os professores têm a tendência de recuperar suas experiências da época na qual eram alunos e construir seus conhecimentos e sua prática de ensino com base nessas lembranças.

Johnson (1994) defende que crenças dos professores advêm das imagens que eles têm da experiência de aprendizagem, das imagens de seus formadores que servem de modelo para sua prática institucional e das imagens deles mesmos como professores. Para Willians e Burden (1997), os professores são influenciados por suas crenças, as quais estão intimamente ligadas aos seus valores, às suas concepções de mundo e de seu lugar dentro dele.

Em seus estudos de crenças, Borg (2003) utiliza o termo cognições de professores para se referir ao que os professores sabem, acreditam e pensam sobre 0 ensino e aprendizagem e sobre sua própria prática. Assim, envolvem o conhecimento dos professores, crenças, teorias pessoais, atitudes, concepções, imagens, percepções e metáforas. As cognições são, de certo modo, moldadas pelas experiências anteriores dos professores, de forma que suas experiências como aprendizes, podem determinar cognições sobre aprender e ensinar, as quais podem acompanhá-los por toda sua carreira. Assim, as cognições e práticas de professores são mutuamente informantes, e fatores contextuais desempenham um importante papel em determinar a extensão pela qual professores são capazes de implementar instruções coerentes com suas cognições. 


\section{Revista do SELL \\ v. $4, n^{\circ} .1$ \\ ISSN: $1983-3873$}

Segundo Borg (2011), crenças são preposições que os indivíduos consideram verdadeiras, são geralmente tácitas, possuem um forte componente avaliativo e afetivo, proveem base para a ação e são resistentes à mudança. As cognições desempenham um papel muito importante na docência de um professor. Elas estão presentes no modo como o indivíduo compreende o mundo, em como novas informações são interpretadas e aceitas ou não. As cognições perpassam o nosso entendimento dos acontecimentos do mundo à nossa volta. Nessa concepção, os professores são indivíduos ativos, capazes de fazer escolhas baseados em um sistema complexo que envolve sua prática, teias de conhecimentos, pensamentos e crenças. Professores trazem consigo, mesmo que de modo inconsciente, crenças sobre todos os aspectos envolvidos em seu trabalho. Assim, o termo cognição de professores refere-se à complexidade da mente dos professores.

Adotamos, neste estudo, uma perspectiva contextual, dinâmica e social das crenças. De acordo com essa perspectiva, acredita-se que as crenças estão interrelacionadas com o meio em que os indivíduos vivem, por fazerem parte de suas experiências. Não estão, portanto, em nível cognitivo somente, mas também social, pois segundo Barcelos (2004, p. 132), elas "nascem de nossas experiências e problemas, de nossa interação com o contexto e da nossa capacidade de refletir e pensar sobre o que nos cerca".

Na seção a seguir, é descrita a metodologia de pesquisa deste estudo.

\section{Metodologia}

Esta pesquisa é de natureza qualitativa. Segundo Teles (2002), considerando que a abordagem qualitativa, enquanto exercício de pesquisa, não se apresenta como uma proposta rigidamente estruturada, ela permite que a imaginação e a criatividade levem os investigadores a propor trabalhos que explorem novos enfoques. O contexto desta pesquisa é a disciplina "Crenças no ensino/aprendizagem de línguas: interfaces afetivas e contextuais", a qual foi ofertada no segundo semestre de 2012, pelo curso de Pós-graduação em Estudos Linguísticos de uma universidade federal no interior de Minas Gerais. Participaram deste estudo sete professoras de línguas e uma professora formadora. 


\section{Revista do SELL}

v. $4, n^{\circ} .1$

ISSN: $1983-3873$

Para coleta de dados foram utilizados um questionário inicial, respondido pelas alunas no primeiro dia de aula, interações realizadas nos fóruns de discussão da disciplina ao longo do semestre, um diário reflexivo no qual as alunas descreveram sua experiência de participação na disciplina após o seu término, e uma discussão na qual as participantes deveriam reler e avaliar seu questionário inicial, refletir sobre suas próprias respostas, expressando se ainda concordavam ou se haviam mudado de opinião e discutir suas percepções acerca de tal questionário com as colegas. Tal discussão foi gravada e posteriormente transcrita. Neste artigo, apresentamos um recorte da análise primária dos dados, a qual consiste na análise dos fóruns de discussão na página da disciplina na plataforma Moodle. Para a análise dos dados, as postagens nos fóruns foram e lidas e classificadas de acordo com temáticas em comum sob o auxílio da ferramenta de análise lexical Word Smith Tools*, de modo a elencar as crenças ali expressas. A figura a seguir ilustra a página inicial na disciplina na plataforma virtual Moodle.

Crenças no ensino/aprendizagem de línguas: interfaces afetivas e contextuais
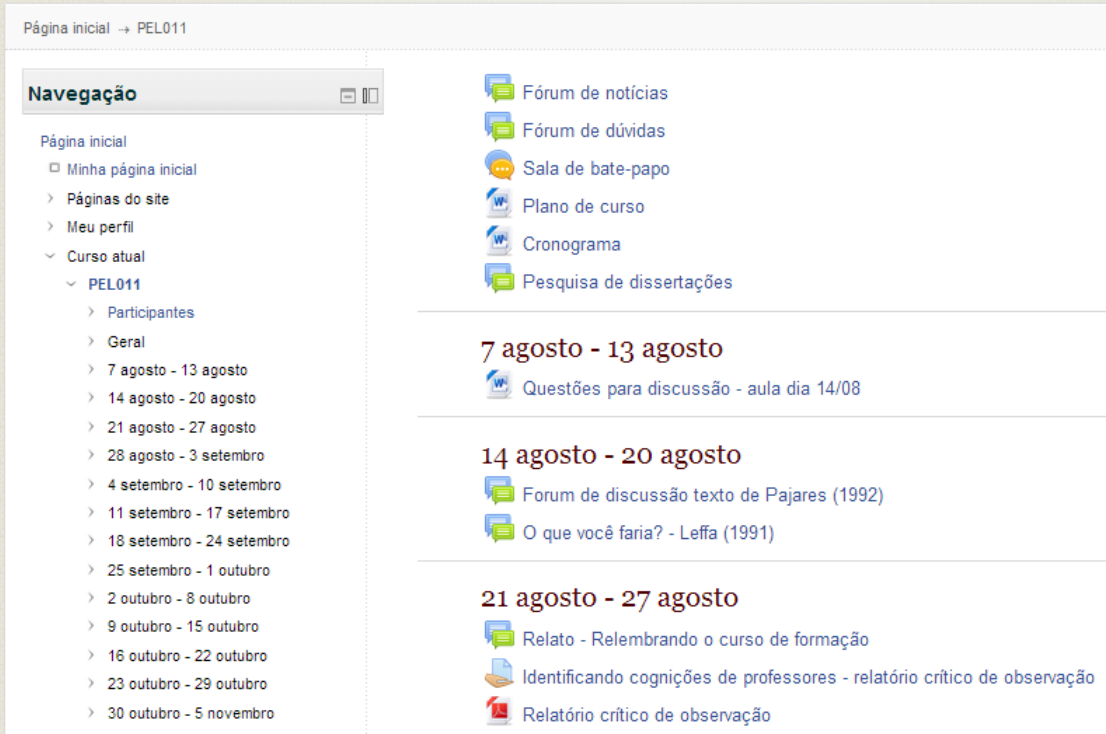

Pesquisar nos Fó

Fórum de dúvidas

Sala de bate-papo

Plano de curso

Últimas noticias

(Nenhuma noticia public

Próximos eventos

Calenc

Atividade recente

Forum de discussão texto de Pajares (1992)

21

Nenhuma novidade des

Figura 1. Página da disciplina no Moodle

*http://www.lexically.net/wordsmith/ 


\section{Revista do SELL}

v. $4, n^{\circ} .1$

ISSN: $1983-3873$

\section{Análise dos dados}

A fim de sintetizarmos a análise das crenças dos professores, tais crenças foram agrupadas em seis temáticas, a saber: o professor e a motivação do aluno; o professor e o currículo; o aluno e sua aprendizagem; a indisciplina dos alunos e a prática docente; as experiências e a prática docente e o professor e as crenças de seus alunos.

Nas discussões dos fóruns, uma das temáticas abordada diz respeito à motivação no ensino e aprendizagem de línguas. Nessas discussões, foi possível observar crenças a respeito da posição do professor em face à motivação do aluno. Diversos pesquisadores têm se dedicado a definir a motivação no ensino e aprendizagem de línguas (DÖRNYEI, 1998; STIPEK, 1998; PINTRICH; SCHUNK, 1996; BZUNECK, 2004). Em comum, tais autores apresentam a ideia de que a motivação é fator de suma importância para que a aprendizagem aconteça. Trata-se de um construto afetivo complexo e multifacetado. De acordo com Pintrich e Schunk (1996), a motivação é definida como um processo que abrange metas que provêm direção à ação e requer atividades que envolvem esforço e persistência.

Para $40 \%$ dos professores é papel do docente motivar o aluno a aprender. Merece destaque o questionamento levando por uma das participantes de que a questão crucial a ser pensada é o "como" motivar esses alunos. 30\% professores acreditam que não é possível ao docente motivar o aluno e 30\% dos professores creem que a responsabilidade pela motivação do aluno não cabe somente ao professor. Já para 10\% deles, atividades contextualizadas com a realidade dos alunos parecem ser uma opção na tentativa de motivá-los, como pode ser lido a seguir:

P1: Eu concordo que uma das grandes funções do professor é justamente estimular o aluno a querer aprender. A questão é: Como o professor pode criar modos que possibilitem que o aluno queira aprender? Que modos são esses? Como estimular o aluno dentro e fora de sala de aula?

P5: Uma outra questão é que acredito que um dos nossos papéis é levar o aluno a se motivar para a aprendizagem da língua. Claro que não conseguiremos envolvimento de todos o tempo integral, mas precisamos buscar formas de mudar o quadro, e mostrar a eles que é possível aprender a língua e a aprendizagem é importante sim para a vida. 


\section{Revista do SELL}

v. $4, n^{\circ} .1$

ISSN: $1983-3873$

P8: Sou da opinião de que o professor pode exercer certa influência na motivação dos alunos, mas como essa é também influenciada por diversos outros fatores, fica difícil responsabilizar unicamente o professor por tudo o que acontece (ou não) na sala de aula. O que sempre me intriga é: nós (porfessoras) conseguimos não nos responsabilizar totalmente pela aprendizagem dos alunos, sem ficar com um certo sentimento de culpa, vergonha por não ter feito mais pelo aluno? Confesso que sempre fico com essa sensação de "dever não cumprido" quando não consigo atingir esses alunos desmotivados. E vocês?

P2: Cada aluno se identifica com uma abordagem, com um aestratégia, com uma proposta diferente. Quando essas identificações coincidem, ótimo, o difícil é isso acontecer. Quando o professor leva um material diferente, boa parte dos alunos pode gostar, mas alguns podem não gostar do que "é novo". Creio que as tentativas são sempre válidas e reitero que quanto mais contextualizada a atividade estiver e quanto mais voltada ela estiver para a realidade dos alunos, mais fácil a identificação mencionada pode ocorrer.

Um aluno motivado é comumente reconhecido por demonstrar interesse e ser participativo nas aulas. Como revela a crença dos participantes, a responsabilidade pela motivação dos alunos não recai apenas no professor. Segundo Zagury (2006) apontar o professor como único responsável pela participação do aluno em aula é mascarar a realidade. Ignorar que por parte dos alunos, há aqueles que, por razões sociais ou pessoais, não querem, não gostam de estudar, e muito menos de se esforçar para aprender, é igualmente ignorar que o ser humano é múltiplo e que cada indivíduo é único e reage diversamente aos estímulos recebidos. E é ignorar também que muitas destas variáveis não podem ser superadas unicamente pelo trabalho do professor, por melhor que ele seja e por mais que trabalhe bem e se esforce muito.

Ao confrontar o professor e o currículo, as crenças apontam que o professor deve aproximar o currículo à vida dos alunos (50\%) e que o professor deve buscar meios de levar o aluno a aprender (40\%). Como exemplificado pelos excertos a seguir:

P2: Provavelmente eu levaria para sala de aula um projeto baseado no contexto dos alunos. Isso significa trabalhar com jogos, música, internet e outros elementos que constituem a cultura vivenciada pelos alunos.

P7: (P1) Eu acredito que um modo seria o professor partir daquilo que o aluno gosta. Se é música, videogame, filme, literatura, sei lá. O ponto seria partir do que $o$ aluno tem prazer em se dedicar e inserir a aprendizagem da língua 


\section{Revista do SELL \\ v. $4, n^{\circ} .1$ \\ ISSN: $1983-3873$}

nesse contexto. Ressalto que isso pode ou não dar certo, porque há inúmeros fatores envolvidos, mas nada impossibilita a tentativa. Você concorda?

Os excertos anteriormente citados além de correlatarem o professor e o currículo, remetem-nos à discussão previamente citada acerca da motivação, visto que, aproximar o currículo à realidade dos alunos, procurar descobrir o que eles gostam e partir de aspectos que os alunos têm prazer em se dedicar são também tentativas de motivá-lo. Como ressaltado por Stipeck (1996) o professor pode, de fato, influenciar a motivação dos alunos. O autor afirma ainda que é função integrante da tarefa docente motivar os alunos, o que pode ocorrer por meio de diversas estratégias, tais como criar um clima emocional positivo em sala de aula, tecer elogios, permitir que os alunos façam escolhas e propor atividades autênticas.

No que concerne ao aluno e sua aprendizagem, os dados assinalam a crença de que o aluno tem que ter papel ativo em sua aprendizagem (30\%). Ao se referirem ao sucesso do aluno, os participantes afirmam que este é marcado por fatores determinantes, tais como motivação e responsabilidade pela aprendizagem (30\%), como apontado pelos trechos que seguem:

P7: O aspecto que eu acredito que preciso modificar é meu papel como professora controladora, não dá mais para tentar ser centro, tentar controlar tudo o que acontece em sala. Na atualidade os alunos tem papel ativo nas aulas e isso precisa ser respeitado. Enfim, o professor não é mais o único que sabe das coisas, os alunos também podem ter bastante bagagem.

P5: Também me vejo nessa condição de controladora, mas tenho tido progressos, já há algum tempo. Isso porque sempre acreditei que os alunos podem assumir o controle também em situações de aprendizagem/.../ Por ser professora há bastante tempo, trago comigo crenças que percebo necessárias de serem desconstruídas, uma delas é esta, a do professor centralizador do processo de ensinar.

Nos depoimentos ilustrados acima, ao refletir sobre sua própria prática docente, transparece a percepção dos professores de que eles se veem como professores controladores e mesmo a consciência de que tal postura precisa ser mudada. Nota-se ainda a crença de que o professor não é o único detentor do conhecimento. Ao nos deparamos com descrições que indicam responsabilidade e papel ativo dos alunos, 


\title{
Revista do SELL
}

v. $4, n^{\circ} .1$

ISSN: $1983-3873$

nos remetemos ao conceito de autonomia. A maioria dos autores concorda com a definição de aprendiz autônomo como sendo aquele que assume um papel ativo em relação ao conhecimento. Segundo Kenny (1993), a visão do que seja autonomia está diretamente ligada à tomada de decisão. Porém, para ele, o papel da autonomia na educação é algo mais do que simplesmente a habilidade de ser responsável. A autonomia também está ligada à escolha, e à ideia de crescimento do aluno. Dickinson (1995), por sua vez, relaciona motivação e autonomia e postula que alunos autônomos se tornam mais motivados e, com isso, a autonomia contribui para um trabalho mais eficiente.

Dentre os fatores que permeiam o dia a dia da prática docente, desponta nos fóruns o fator indisciplina, e junto a ele, as seguintes crenças: a indisciplina é um dos maiores problemas do ensino (20\%); a indisciplina frustra professores (20\%); postura autoritária e punitiva ajudam a manter a disciplina (20\%); a indisciplina não deve ser vista de forma tão negativa (10\%). Observemos os trechos na sequência:

\begin{abstract}
P3: Um dos maiores problemas em lecionar hoje em dia é a indisciplina, o que todos dizem. Mas, que indisciplina é essa? Acho que é preciso pensar nisso, qual o conceito de indisciplina? Muitos acreditam que se a aluno é agitado ele é indisciplinado. Parece que no final das contas se o aluno não fica sentado o tempo todo fazendo o que o professor propõe qualquer coisa é indisciplina. Sei que há muitos problemas de comportamento, mas há muitos problemas com o que a escola oferece para os alunos. Tenho alunos ótimos e alunos muito fracos na mesma sala e o que eu ofereço para um não chega fica muito aquém do que o outro quer e consegue. O que fazer? Dois planos?Duas aulas em uma? Para mim, é fato que as aulas, de todas as disciplinas, precisam ser mais dinâmicas, assim como o mundo de hoje. Mas como fazer isso? Ainda estou tentando descobrir.
\end{abstract}

P1: Só não concordava com sua postura punitiva, em atribuir nota a qualquer coisa e ameaçar os alunos, mas entendo que era a maneira que ele tinha de lidar com a indisciplina, pelo que eu vi, os alunos só prestavam atenção e faziam se houvesse nota.

Os professores revelam que a indisciplina, definida por eles como problemas no comportamento, é um dos grandes problemas para quem trabalha com o ensino. Outros estudos já haviam apontado o fator indisciplina dos alunos como obstáculo à motivação dos professores (RIBAS, 2012). Os professores demonstram ainda incertezas e dúvidas em como lidar com tal problema e, ao relatarem suas experiências de 


\title{
Revista do SELL \\ v. $4, n^{\circ} .1$ \\ ISSN: $1983-3873$
}

aprendizagem, revelam que, muitas vezes, por não conseguirem lidar com a indisciplina, seus professores recorriam a uma postura punitiva, o que pode ter interferido em suas próprias crenças e prática docente.

Discussões acerca do professor e as crenças dos seus alunos também emergiram nos fóruns. Os participantes acreditam que o professor tem o poderio de influenciar as crenças dos alunos e, além disso, de transformá-las (70\%):

\begin{abstract}
P4: O papel do professor é apontar possibilidades ao aluno para que ele aprenda de várias formas, que não fique preso a uma crença específica. Eu penso que podemos como professor trabalhar as crenças do aluno porque é a partir de novas experiências com a aprendizagem que o aluno pode enxergar a língua sob outra perspectiva.
\end{abstract}

P5: (P1), lendo sua resposta, eu pensei também que o professor pode transferir para a aprendizagem do aluno, aquele "eu" que ele tem como ideal. Em nossa prática, muitas vezes, temos um modelo de falante de língua inglesa que nem nós mesmos conseguimos ser, mas almejamos isso para o nosso aluno.

P6: Mostrar outras estratégias de aprendizagem é de extrema importancia, para os estudantes não ficarem limitados a repetições e o uso de diciónarios sempre. Assim, inferir palavras pelo contexto, explorar músicas, principalmente relatando a sonoridade das palavras e ainda usar a internet como forma de explorar mais o vocabulário da lingua, podem ajudar a trabalhar com algumas crenças estabelecidas.

Os professores se veem no papel de trabalhar as crenças que os alunos possuem ao possibilitá-los novas experiências e admitem que, por vezes, acabam transmitindo suas crenças aos alunos. De modo semelhante, Woods (2003) argumenta que o professor pode influenciar nas crenças dos alunos. $O$ autor defende que a postura do professor pode alterar as crenças dos alunos e apresenta algumas sugestões para que isso ocorra, tais como tornar as crenças dos alunos explícitas para análise, exame e reflexão e planejar eventos que possam ser interpretados de forma que façam sentido para o aluno, de modo que os force a revisar alguns elementos de seu conjunto de crenças atual.

Ao relacionarmos experiências e prática docente, as crenças dos professores revelam que experiências positivas ou negativas, respectivamente, motivam e desmotivam o professor (30\%), e ainda, ao refletirem sobre sua formação docente, 


\section{Revista do SELL \\ v. $4, n^{\circ} .1$ \\ ISSN: $1983-3873$}

revelam que o professor aprende com sua experiência no dia a dia sala de aula (20\%). Se, por um lado, experiências negativas, tais como a indisciplina, desmotivam o professor, notar valorização em seu trabalho e percepção de sucesso dos seus alunos o motivam. Tais crenças podem ser identificadas a seguir:

P4: Penso que o aspecto emocional exerce uma influência pontual no processo de ensinar (e de aprender, é claro!). Temos necessidade de perceber que nossos esforços não são em vão. O que mais nos satisfaz, enquanto professores, é a resposta de nossos alunos, traduzida em aprendizagem e crescimento pessoal /.../ Não há nada mais motivador que você ter resultados satisfatórios e também poder adquirir a confiança/valorização daqueles para quem se destina o seu trabalho.

P5: Concordo com a (P4), (P1)! Se acreditamos que a forma como ensinamos tem surtido efeitos positivos, tenderemos a continuar nessa linha da ação. /.../ No caso do professor, saber que contribuiu para a aprendizagem do aluno, que seus objetivos foram alcançados pode gerar um sentimento de que o seu trabalho é importante e que vale a pena investir nele. Quem é que não teve a experiência de levar algo diferente para a aula que tenha sido eficaz e que tenha proporcionado uma aula agradável? A sensação de dever cumprido e a experiência positiva podem funcionar como uma recompensa pelo trabalho empenhado e motivar ainda mais a preparação de aulas futuras.

De acordo com Dörnyei (2001) fatores internos (cognitivos) e externos (contextuais) podem influenciar a motivação do professor. Dentre os fatores internos, tal como revelado pelos excertos acima, a sensação de poder contribuir para o desenvolvimento dos alunos e perceber o entusiasmo e disposição dos alunos ao responder a uma tarefa podem ser fortes recursos de satisfação para o professor (DECl, KASSER; RYAN, 1997).

Nota-se que os fóruns de discussão, os quais foram empregados como meio de comunicação entre alunos e professores se alicerçaram como espaço capaz de promover discussões e dar continuidade às reflexões iniciadas em sala de aula. Nesse quesito, merecem destaque os questionamentos levantados pelos alunos para que os colegas pudessem opinar e mesmo o convite a que os colegas se posicionassem, o que é notado através das constantes interrogações e de expressões como "eu concordo com...", "lendo sua resposta, eu pensei...", "eu acho que... e vocês?", ou ainda ao citar o nome e 


\section{Revista do SELL}

v. $4, n^{\circ} .1$

ISSN: $1983-3873$

trechos de postagens de outros colegas, atitudes essas que puderem ser observadas em todos os fóruns.

\section{Considerações finais}

Orientados por um professor formador, nesta disciplina, os professores de línguas, ocupando o papel de alunos, e embasados por um estudo teórico sobre crenças, puderam partilhar experiências, discutir e refletir sobre suas crenças e as crenças dos colegas, a partir da metodologia proposta. Conhecer e interpretar as crenças pode ser um caminho rumo à transformação do trabalho docente e à prática reflexiva.

Embora divergentes em apontar a possibilidade e/ou responsabilidade do professor em motivar o aluno, as crenças dos professores convergem para a importância da motivação para que a aprendizagem aconteça. Os professores nutrem a crença de que devem buscar meios de levar o aluno a aprender, e de que têm o poder e o dever não apenas de influenciar, mas também de transformar as crenças dos alunos. As crenças dos professores apontam ainda o perfil de um "aluno ideal", ativo, responsável e motivado para que a aprendizagem seja bem sucedida. Ao refletirem acerca de sua própria motivação, os professores revelaram que experiências positivas e/ou negativas interferem na motivação docente. Dentre essas experiências têm destaque, de um lado, a indisciplina e, de outro, o bom desempenho e interesse dos alunos.

Diante do interesse e, sobretudo da necessidade, de busca por novas perspectivas na formação de professores de línguas em meio à era digital, explorar a plataforma Moodle parece ser um recurso em potencial. As possibilidades educacionais trazidas pelos fóruns de discussão oportunizam transpor as paredes da sala de aula, ampliar e aprofundar discussões e mesmo fortalecer o vínculo entre os alunos. Os fóruns de discussão se mostraram como um aliado na formação docente, o qual permite que os alunos possam partilhar experiências, refletir sobre suas próprias crenças e as crenças dos colegas, por meio de um percurso metodológico que os conduziu a ler, debater, refletir e postar acerca de questões teóricas e práticas. 


\section{Revista do SELL}

v. $4, n^{\circ} .1$

ISSN: $1983-3873$

\section{Referências}

ALVAREZ, M. L. O. Crenças, motivações e expectativas de alunos de um curso de formação Letras/Espanhol. In: ALVAREZ, M. L. O. ; SILVA, K. A. (Org.). Linguística Aplicada: Múltiplos Olhares. Campinas, SP: Pontes, p. 167-190, 2007.

BARCELOS, A. M. F. Crenças sobre aprendizagem de línguas, Linguística Aplicada e ensino de línguas. Linguagem e Ensino, v. 7, n. 1, p. 123-156. 2004.

- Cognição de professores e alunos: tendências recentes na pesquisa de crenças sobre ensino e aprendizagem de línguas. In: BARCELOS, A. M. F.; VIEIRAABRAHÃO, M. H. (Orgs.). Crenças e Ensino de Línguas: Foco no professor, no aluno e na formação de professores. Campinas, SP: Pontes Editores, p. 15-42, 2006.

Reflexões acerca da mudança de crenças sobre ensino e aprendizagem de línguas. Revista Brasileira de Linguística Aplicada. Belo Horizonte, v. 7, n. 2, 2007.

BORG. S. Teacher cognition in language teaching: A review of research on what teachers think, know, believe and do. Language Teacher. Cambridge, v. 36, 2003, p. 81-109.

The impact of in-service teacher education on language teachers' beliefs. System, v. 39, p. 370-380, 2011

BZUNECK, J. A. A motivação do aluno: aspectos introdutórios. In: BORUCHOVITCH, E.; BZUNECK, A. (Org.). A motivação do aluno: contribuições da psicologia contemporânea. 3. ed. Petrópolis: Vozes, 2004.

DECI, E. L.; KASSER, T.; RYAN, R. M. Self-determined teaching: opportunities and obstacles. In: BLESS, James L. (Ed.). Teaching well and liking it: motivating faculty to teach The motivation of EFL public school teachers effectively. Baltimore, USA: The Johns Hopkins University Press, 1997, p. 57-71.

DICKINSON, L. Autonomy and Motivation: A Literature Review. System, vol. 23, n. 2, p.165-174, 1995.

DORNYEI, Z. Motivation in second language learning and teaching. Cambridge University Press, 1998.

GABILLON, Z. L2 learner'sbeliefs: An overview. Journal of Language and Learning, v. 3, p. 233-260, 2005.

JOHNSON, K. E. The emerging beliefs and instructional practices of Preservice English as a second language Teachers. Elsevier Science, v. 10, p. 439-452, 1994.

KENNY, B. For More Autonomy, System, vol. 21, n 4, p.431-442, 1993.

PAJARES, M. F. Teacher's beliefs and educational research: cleaning up a messy construct. Review of Educational Research, v. 62, n. 3, p. 307-332, 1992.

PINTRICH, P. R.; SCHUNK, D.H. Motivation in Education: theory, research, and applications. Englewood Cliffs, N.J: Prentice Hall, 1996, 


\section{Revista do SELL}

v. $4, n^{\circ} .1$

ISSN: $1983-3873$

RIBAS, F. C. The motivation of EFL public school teachers: what can self-theories tell us?. Horizontes de Linguística Aplicada, v. 11, p. 13-38, 2012.

STIPEK, D. J. Motivation and instruction. In: BERLINER, D. C.; CALFEE, R. C. (Eds.). Handbook of educational psychology. New York: Macmillan, 1996, p.85-113.

TELLES, J.A. "É pesquisa, é? Ah, não quero, não, bem!" Sobre pesquisa acadêmica e sua relação com a prática do professor de línguas. Revista Linguagem \& Ensino, v. 5, n. 2, 2002.

ZAGURY, T. O Professor refém: para pais e professores entenderem porque fracassa a educação no Brasil. Rio de Janeiro: Record, 2006.

VIEIRA-ABRAHÃO, M. H.. Crenças $x$ teorias na formação pré-serviço do professor de língua estrangeira. In: TOMITCH, L. M. B.; VIEIRA-ABRAHÃO, M. H.; DAGHLIAN, C.; RISTOFF, D. I. (Orgs.). A interculturalidade no ensino de inglês. Florianópolis, UFSC, 2005.

Metodologia na investigação das crenças. In: BARCELOS, A.M.F.;

Crenças e ensino de línguas: foco no professor, no aluno e na formação de professores. Campinas: Pontes, 2006, p. 219-231.

Cognição de professores de línguas: formação, fatores contextuais e práticas de sala de aula. Contexturas, v. 16, p. 113-134, 2010.

WILLIANS, M.; BURDEN, R. Psychology for language teachers. Cambridge University Press, 1997.

WOOD, D. The social construction of beliefs in the language classroom. In: KALAJA; P; BARCELOS. A. M. F. (Ed.). Beliefs about SLA: New Research Approaches. Dordrecht: Kluwer, 2003, p. 201-229. 